\title{
Influence of Acute Hemodynamic Changes on the Peak Velocity of Contractile Element Shortening and Maximum Velocity Obtained by the Calibrated Apex Cardiography in Dogs ${ }^{\dagger}$
}

\author{
Nikolai S. Kolev, M.D., Georgi K. Uzunov, M.D., \\ Vlasaki L. Vlasakov, M.D., and Janeta G. Tijaneva, M.D.
}

\section{Summary}

The effect of various alterations in preload, afterload and inotropic state of the left ventricle on the noninvasive peak velocity of contractile element shortening ( $\mathrm{Vpm}$ ) and maximum velocity of contractile element shortening (Vmax) was studied in the anesthetized dogs in an attempt to test the methods and clarify some of the determinants of these parameters. Calibrated displasement left apex cardiogram obtained with time constant $3 \mathrm{sec}$ and calibrated first derivative of apex cardiogram were recorded simultaneously with left ventricular pressure and its first derivative, electrocardiogram and phonocardiogram.

The values of $\mathrm{Vpm}$ obtained from catheterization and calibrated apex cardiography were similar in magnitude and standard deviations under various hemodynamic interventions. A highly significant relation was found between these invasive and noninvasive parameters of myocardial contractility. Both Vpm and Vmax were elevated during the administrations of isoprenaline and strophanthin, where only Vpm showed a decrease after extreme volume or pressure load.

In conclusion, the results from this study suggest that $\mathrm{Vpm}$ and Vmax of the calibrated apex cardiography are a reliable noninvasive tool for assessing left ventricular function; furthermore, $\mathrm{Vpm}$ is relatively load independent, whereas $\mathrm{Vmax}$ is virtualy unchanged over a broad range of loading conditions.

\section{Additional Indexing Words:}

Apex cardiogram First derivative Forse-velocity relation

TN recent years, methods have been developed for calibration of the displacement left apex cardiogram (ACG) and its first derivative (dA/dt). ${ }^{1-3)}$ By

From the Medical Academy, Higher Medical Institute, Department of Internal Medicine, 9002 Varna, Bulgaria.

† Basic details of this study were presented at the ISM Conference, April 9-12, 1981.

Received for publication March 31, 1981. 
using calibrated tracings, the $\mathrm{dA} / \mathrm{dt}$ appeared to be related to left ventricular function, and its positive height has been shown to correlate significantly with positive peak $\mathrm{dA} / \mathrm{dt}^{, 2), 3)}$ furthermore, it was demonstrated the clinical value of index $\mathrm{dA} / \mathrm{dt} / \mathrm{A} .{ }^{1{ }^{1-4)}}$

In order to use noninvasively the informative values of peak velocity of contractile element shortening $(\mathrm{Vpm})$ and maximum velocity of contractile element shortening ( $V \max )$, we proposed a new way of their estimation. The amount of $\mathrm{Vpm}$ and $\mathrm{Vmax}$ was assessed by adapting the conventional catheterization method $^{\text {(1-9) }}$ utilizing calibrated displacement ACG and its first derivative.

The present study was undertaken to examine noninvasively indices $\mathrm{Vpm}$ and Vmax obtained by calibrated displacement apexcardiography in dogs, specificaly with respect to pre- and afterload dependence.

\section{Materials AND Methods}

\section{Experimental protocol}

The experiments were carried out in 9 adult male and female mongrel dogs which weighed from 14 to $27 \mathrm{Kg}$ (average $19 \mathrm{Kg}$ ). The animals were anesthetized with Thiopental $(20 \mathrm{mg} / \mathrm{Kg})$ infused intravenously with supplement as needed, $45 \mathrm{~min}$ after an injection of morphine sulphate ( $2 \mathrm{mg} / \mathrm{Kg}$ ). Coagulation was prevented by an initial dose of sodium heparin $30 \mathrm{mg} / \mathrm{Kg}$ followed by $10 \mathrm{mg}$ doses hourly. Artificial positive pressure respiration was instituted through a tracheal cannula. Dogs were in the left recumbent position and during recording of the left apex cardiogram the respirator was stopped for 20 to $120 \mathrm{sec}$.

Each dog was subjected to different procedures; short acting drugs or interventions were usually imposed first, and sufficient time was allowed for recovery. Changes primarily affecting afterload of the left ventricle were induced through balloon occlusion of descending aorta by means of rapid manual inflation of 30 to $40 \mathrm{ml}$ air for $0.2-2 \mathrm{~min}$ into a rubber balloon mounted at the tip of a rigid catheter positioned in the aorta by way of right femoral artery. Effect of altering inotropic background were elicited by intravenous injection of isoprenalin (50 to $200 \mu \mathrm{g}$ ) and strophanthin (1/32 to $1 / 16 \mathrm{mg}$ ). Changes in preload were provoked through balloon occlusion of the inferior vena cava at a level of the diaphragm via right femoral vein and by rapid intravenous infusion of 400 to $1600 \mathrm{ml} \mathrm{6 \%}$ dextran at the end of experiment.

Recording equipment and measurements

In all experimental animals left ventricular pressure were recorded through well flushed $100 \mathrm{~cm}$ no 7 and 8 catheters with Statham P23D trans- 
ducer balanced at the mid-chest level. The strain gauge and electromanometer Hellige (GBR) were calibrated before each experiment. The first derivative of left ventricular pressure $(\mathrm{dp} / \mathrm{dt}$ ) was obtained using an $\mathrm{RC}$ differentiating circuit with a $1 \mathrm{msec}$ time constant and an output lineary proportional to the imput, within $5 \%$, up to a frequency of 75 cycles/sec. Catheters were flushed carefuly with heparinized saline and only tracings free from obvious catheter artefacts were analyzed.

The derivation $\mathrm{dP} / \mathrm{dt} / 24 \cdot \mathrm{P}$ as an approximation of contractile element shortening velocity (VCE) during isovolumic systole has been discussed by Ross et al ${ }^{10}$ and Taylor et al. ${ }^{11} \quad \mathrm{P}$ was calculated using developed pressure measured with reference to the level of end-diastolic pressure (Fig. 1). ${ }^{12}$ Details of measurements of Vpm and Vmax have been described elsewhere. ${ }^{51-9)}$

Used in this study fluid filled catheters are known to introduce distorsion (change in wave form) and phase shift (time delay) in the transmitted signal. ${ }^{13}$ ) Since no quantitative estimates of the error in Vmax introduced by catheter responce were available, the error was estimated in the following way. The observed left ventricular pressure was expressed as a Fourier series including 20 harmonics. ${ }^{13)}$ Typically the amplitude of the tenth harmonics was $1 \%$. The addition of 10 more harmonics to the Fourier analysis did not change the results. The observed pressure was corrected for various values of catheter natural frequency and damping ratio. The corrected pressure was used to calculate Vmax (based on pressure data alone). This was compared with the value from the original wave form.

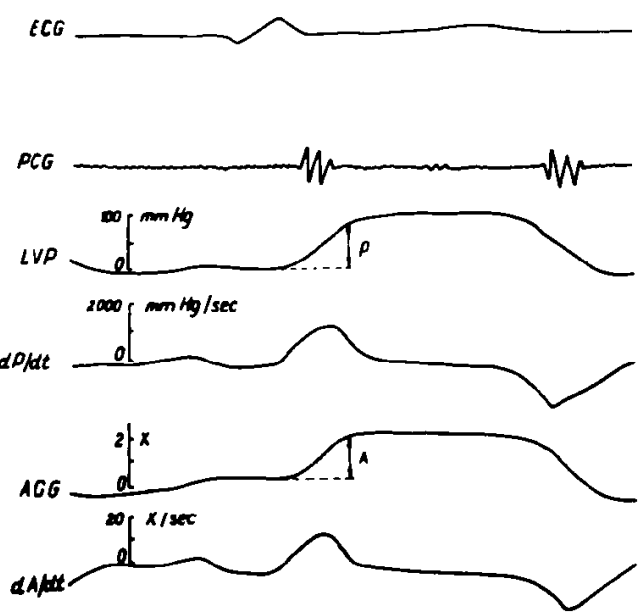

Fig. 1. Simultaneous high-speed tracings $(200 \mathrm{~mm} / \mathrm{sec})$ of electrocardiogram (ECG), phonocardiogram (PCG), left ventricular pressure (LVP), first derivative of left ventricular pressure $(\mathrm{dp} / \mathrm{dt})$, calibrated displacement left apex cardiogram (ACG), and its first derivative (dA/dt). P denotes developed LVP and $\mathrm{A}$ equals developed apex cardiographic isovolumic amplitude. 
Fig. 2 summarize the results of the error estimate. The percent difference between the corrected and uncorrected values of Vmax is plotted as a function of the natural frequency for two values of damping ratio, B. This error is caused by distorsion only; phase shift does not affect the calculation since $V \max$ is obtained from a plot of $\mathrm{dP} / \mathrm{dt} / \mathrm{k} \cdot \mathrm{P}$ versus $\mathrm{P}$. Increased damping reduces the error for any given natural frequency. Except for very low natural frequencies, less than $10 \mathrm{cycles} / \mathrm{sec}$, the fluid-filled catheter system overestimates the rate of pressure rise and, hence, Vmax.

The transducer manufacturer estimates a natural frequency of 70 cycles/ sec and a damping ratio of 0.3 for the catheter and transducer used in the present study.* These values are probably better than those obtained in actual application. It is estimated that the catheter system used here had a natural frequency above 20 cycles/sec, with damping ratios greater than 0.2 . This would correspond to an expected error of less than $14 \%$ in the reported values of Vmax.

The left apex cardiogram were recorded by means of a piezoelectric transducer (RFT, GDR) with an time constant $3 \mathrm{sec}$. The transducer was held manually at a point of maximal impulse of the beat of the heart. The first derivative of apex cardiogram was obtained by means of $\mathrm{RC}$ differentiating circuit with time constant of $1 \mathrm{msec}$ and a flat responce in a range of 0 to 70 cycles/sec.

For calibration of $\mathrm{ACG}$ and $\mathrm{dA} / \mathrm{dt}$, electric potential slope generated from the battery-resistance-capacitance circuit was used (Fig. 3). The ACG and $\mathrm{dA} / \mathrm{dt}$ are expressed in relative units using calibration by triangular wave

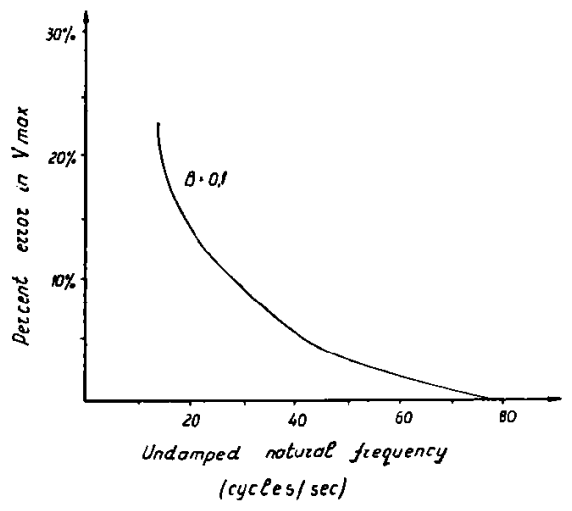

Fig. 2. Estimated error in Vmax caused by limited dynamic response of catheter system. The error is calculated from a Fourier analysis of the measured pressure corrected term-by-term for attenuation and phase shift. $B=$ the fraction of critical damping.

* Statham Laboratories, Inc, Product Bulletin MP 109, September 1969. 


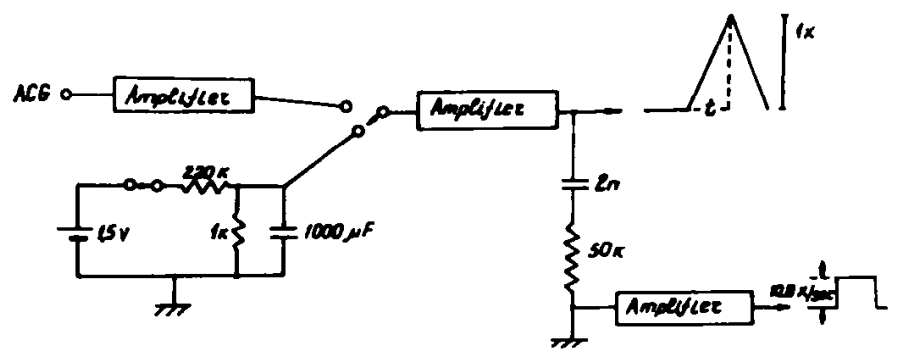

Fig. 3. Method for calibration of apex cardiogram and its first derivative.

form with a slope of $4 \mathrm{~V} / \mathrm{sec}$ and amplitude of $1 \mathrm{~V}$. This ramp-signal passes through the same differentiating circuit as the pulse wave and both signals are recorded on paper. The height of the triangular signal in $\mathrm{mm}$ serves as a calibration factor (1X) and the height of the ACG is expressed as a factor of $\mathrm{X}$. By using the time ( $t$ ) from the nadir to the top of the ramp signal (in Fig. 3, $t$ equals $92 \mathrm{msec}$ ), the calibration signal for the $\mathrm{dA} / \mathrm{dt}$ can be expressed as a value of $\mathrm{X} / \mathrm{sec}$ (in Fig. 3 the height of the calibration factor equals $10.8 \mathrm{X} /$ sec). See also Fig. 1.

Adapting the catheterized formula for $\mathrm{VaE}$, we obtained non-invasively $\mathrm{VCE}$ from calibrated $\mathrm{dA} / \mathrm{dt}$ and its corresponding values of calibrated apex cardiographic amplitude $A$ by the equation $V \mathrm{CE}=\mathrm{dA} / \mathrm{dt} / \mathrm{k} \cdot \mathrm{A}$, expressed in $\mathrm{sec}^{-1}$. In a given formula $\mathrm{k}$ is the normalized modulus of series elesticity of the intact left ventricle and has been found experimentaly to average 24.7),9 When $\mathrm{dA} / \mathrm{dt} / \mathrm{k} \cdot \mathrm{A}$ measured during an ejection period (from the closure of the mitral valve to the point of the opening the semilunar valve) is plotted as the ordinate against $\mathrm{A}$ as the abscissa, a modified non-invasive force-velocity curve is obtained (Fig. 4). Our method is contributed by the statement of Wolk et $\mathrm{a}^{\text {1) }}$ for estimation of $V \max$, that it is not necessary to calculate absolute values for abscissa and ordinata as long as the first derivative is calibrated with reference to the primary curve. The closure of the mitral valve is determined by the first large, higher frequency vibrations of the first heart sound and the opening of the aortic valve- by the E point of ACG. ${ }^{14), 15)}$ To obtain the foce-velocity curve it is necessary to measure the value of each variables at $5 \mathrm{msec}$ intervals, using recording at a paper speed of $200 \mathrm{~mm} / \mathrm{sec}$.

Determination of Vmax from such phase plot was made as follows. With phase plots of $\mathrm{dA} / \mathrm{dt} / \mathrm{k} \cdot \mathrm{A}$ on the ordinate versus amplitude of $\mathrm{A}$ on the abscissa were in general inversely curvelinear after the inscription of peak velocity of contractile element shortening ( $\mathrm{Vpm}$ ) or peak VCE, the shape of inverse curve between peak $V_{C E}$ and aortic valve opening varied from a nearly linear inverse relation to a shallow concave-upward curve. For this reason, we have 

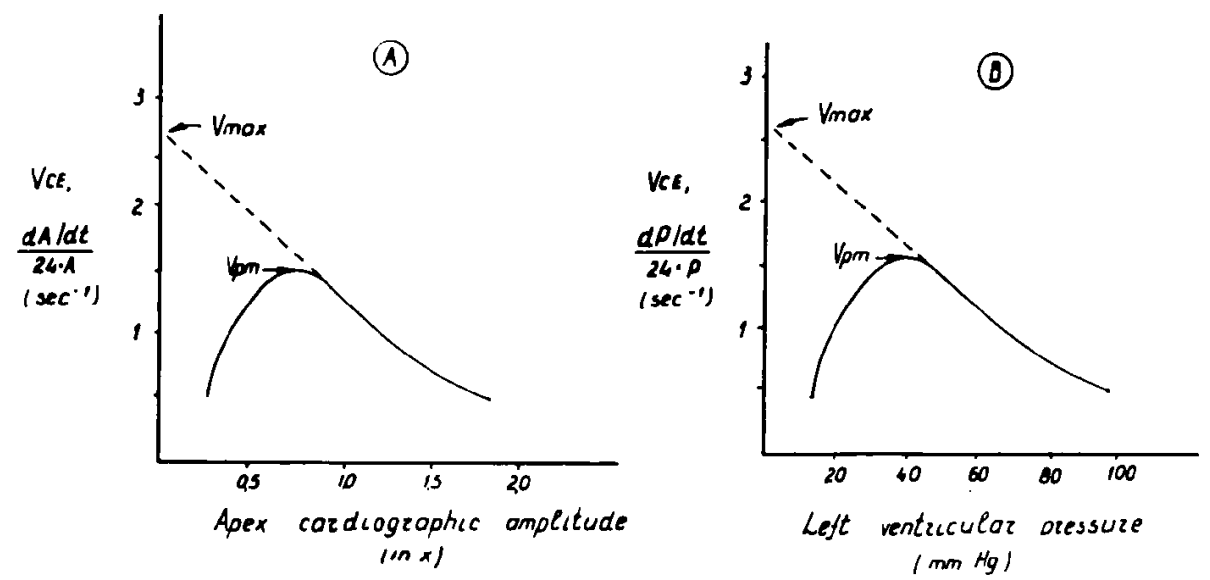

Fig. 4. Example of a plot of noninvasive Vc against calibrated isovolumic apex cardiographic amplitude (A) and Vve versus isovolumic pressure (B) from a representative beat. $\mathrm{Vpm}$ denotes the physiologic maximal velocity of shortening and $\mathrm{Vmx}$ (velocity shortening at zero load) is obtained by extrapolation on $y$ axis with broken lines, drawn by eye.

followed the technique of Mason et $\mathrm{al}^{51,6)}$ and Wolk et al, ") whereby extrapolation of the curve to the velocity axis intercept (Vmax) was accomplished by hand and consisted of a smooth extension of the best line drown throught the inverse portion of the experimentaly obtained phase plot. Although some authors perform the extrapolation to $V \max$ mathemetically, using the Hill equation, another experiments ${ }^{16}$ ) have cast doubt on the applicability of this equation to the heart muscle. Parameters $\mathrm{A}$ on the abscissa are calculated using developed amplitudes of isovolumic portion of $\mathrm{ACG}^{2), 3)}$ which is measured with the $\mathrm{C}$ point of ACG as a reference zero line (Fig. 1). The value of $\mathrm{Vpm}$ and Vmax are expressed in circ/sec.

The electrocardiogram, was obtained by means of subcutaneous needles. Apical external phonocardiogram 140 cycles/sec were recorded with piezoelectric transducer (RFT, GDR).

The electrocardiogram, phonocardiogram, apex cardiogram, left ventricural pressure and their first time derivatives were recorded on an 6-channel carbon recorder 6 NEK-3 (GDR), simultaneously and continuously before, during and after various interventions. Paper speed was $200 \mathrm{~mm} / \mathrm{sec}$.

For each measurement the average of at least 5 separate cardiac cycles were used. After conversion of experimental data to digital form, all calculations were performed by an IBM 370 computor using standard statistical methods. 


\section{Results}

The ratio $\mathrm{dA} / \mathrm{dt} / \mathrm{k} \cdot \mathrm{A}$ was plotted against instantaneous isovolumic callibrated apex cardiographic amplitudes every $5 \mathrm{msec}$ for each hemodynamic variation from the closure of the atrio-ventricular valve to the opening of the semilunar aortic valve. At the time of initial phase of isovolumic contraction, both values of $A$ and $V C E$ progressively increased until a peak is attained approximately 30-35 msec from the onset of isovolumic systole. During latter stages of isovolumic systole non-invasive force-velocity curve progressively declines. Fig. 4 shows an example of a plot of VCE obtained from calibrated apexcardiography versus developed isovolumic amplitude of ACG (A) and a plot of VCE against developed left ventricular pressure (B). It can be seen

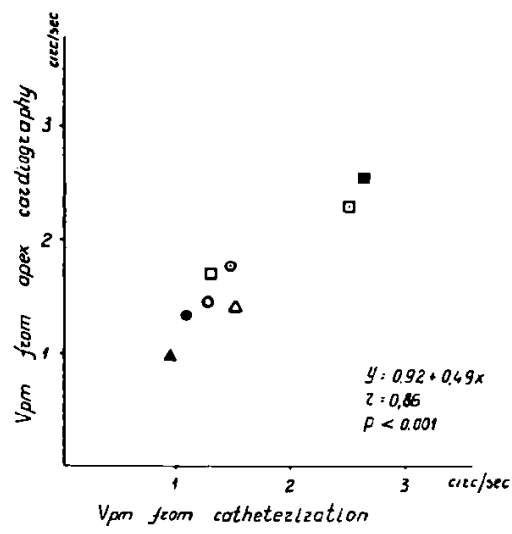

Fig. 5. Relation between invasive and noninvasive Vpm. $\square=$ control state; $O=$ occlusion dec. Ao subrange I; $=$ occlusion dec. Ao subrange II; $\boldsymbol{D}=$ isoprenalin; $\nabla=$ strophanthin; $\Theta=$ vena caval occlusion; $\Delta=$ volume load subrange I; $\boldsymbol{\Lambda}=$ volume load subrange II.

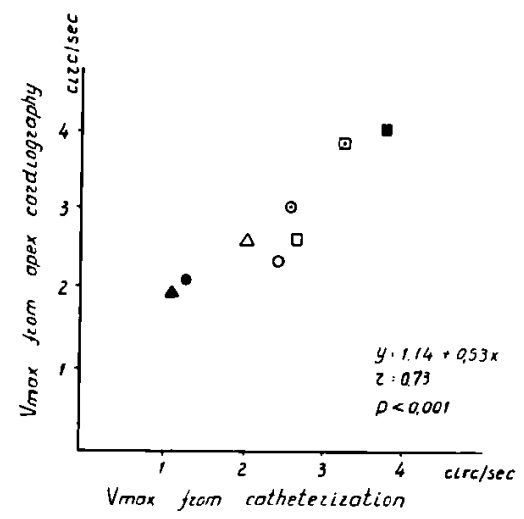

Fig. 6. Relation between invasive and noninvasive Vmax. Symbols as in Fig. 5. 
that the general course were similar in representative dog cardiac cycle. A close relation was found between $\mathrm{Vpm}$ derived from left ventricular pressure and $\mathrm{dP} / \mathrm{dt}$ and those from calibrated apex cardiogram and its first derivative (Fig. 5). A nearly significant linear correlation was presented between catheterized and non-invasive Vmax (Fig. 6).

The combined results of different interventions on Vpm and Vmax derived from left ventricular catheterization and calibrated left apex cardiography are summarized in Table $\mathrm{I}$. The total range of the left ventricular end-diastolic pressure (LVEDP) produced either by pressure or volume loading was divided into a two subranges (subrange I, 14-23 $\mathrm{mmHg}$; subrange II 24-38 $\mathrm{mmHg}$ ). In subrange I there were no significant decrease in both Vpm and Vmax, but at higher LVEDP (subrange II) Vpm were depressed significantly $(\mathrm{p}<0.05)$.

Table I. Summary of Changes of Apex Cardiographic and Catheterized Peak Velocity of Contractile Element Shortening (Vpm) and Maximal Velocity Shortening (Vmax) in Dogs with Corresponding Changes in Heart Rate (HR), Left Ventricular End-Diastolic Pressure (LVEDP) and Mean Aortic Pressure (MAP)

\begin{tabular}{|c|c|c|c|c|c|c|c|}
\hline & \multirow{2}{*}{$\begin{array}{c}\mathrm{HR} \\
\text { (beats/ } \\
\text { min) }\end{array}$} & \multicolumn{2}{|c|}{ Apex cardiographic } & \multicolumn{2}{|c|}{ Catheterized } & \multirow{2}{*}{$\begin{array}{c}\text { LVEDP } \\
(\mathrm{mmHg})\end{array}$} & \multirow{2}{*}{$\underset{(\mathrm{mmHg})}{\mathrm{MAP}}$} \\
\hline & & $\begin{array}{c}V p m \\
(\operatorname{circ} / s e c)\end{array}$ & $\underset{(\mathrm{circ} / \mathrm{sec})}{V \max }$ & $\underset{(\operatorname{circ} / \mathrm{sec})}{\mathrm{Vpm}}$ & $\underset{(\operatorname{circ} / \mathrm{sec})}{V \max }$ & & \\
\hline Control state & $107 \pm 12$ & $\begin{array}{l}1.76 \pm \\
0.54\end{array}$ & $\begin{array}{l}2.87 \pm \\
0.92\end{array}$ & $\begin{array}{l}1.38 \pm \\
0.42\end{array}$ & $\begin{array}{l}2.59 \pm \\
0.85\end{array}$ & $\begin{array}{l}9.4 \pm \\
3.5\end{array}$ & $101 \pm 18$ \\
\hline \multicolumn{8}{|c|}{ Occlusion des. Ao } \\
\hline Subrange I & $102 \pm 13$ & $\begin{array}{l}1.51 \pm \\
0.62\end{array}$ & $\begin{array}{l}2.45 \pm \\
0.75\end{array}$ & $\begin{array}{l}1.36 \pm \\
0.45\end{array}$ & $\begin{array}{l}2.32 \pm \\
0.83\end{array}$ & $\begin{array}{c}17.3 \pm \\
5.2 \dagger\end{array}$ & $162 \pm 21^{*}$ \\
\hline Subrange II & $86 \pm 10$ & $\begin{array}{l}1.33 \pm \\
0.26\end{array}$ & $\begin{array}{l}1.01 \pm \\
0.80 \dagger\end{array}$ & $\begin{array}{l}1.21 \pm \\
0.62\end{array}$ & $\begin{array}{l}1.27 \pm \\
0.93 \bar{t}\end{array}$ & $\begin{array}{c}28.1 \pm \\
5.2^{*}\end{array}$ & $190 \pm 23^{*}$ \\
\hline Isoprenalin & $172 \pm 19 *$ & $\begin{array}{l}2.80 \pm \\
0.45^{*}\end{array}$ & $\begin{array}{l}4.05 \pm \\
0.95^{*}\end{array}$ & $\begin{array}{l}2.75 \pm \\
0.39^{*}\end{array}$ & $\begin{array}{l}3.26 \pm \\
0.87^{*}\end{array}$ & $\begin{array}{l}5.0 \pm \\
1.2\end{array}$ & $111 \pm 17$ \\
\hline Strophanthin & $105 \pm 10$ & $\begin{array}{l}2.35 \pm \\
0.63 t\end{array}$ & $\begin{array}{l}3.92 \pm \\
0.88 \dagger\end{array}$ & $\begin{array}{l}2.70 \pm \\
0.50 t\end{array}$ & $\begin{array}{l}3.70 \pm \\
0.82^{*}\end{array}$ & $\begin{array}{l}7.3 \pm \\
3.5\end{array}$ & $110 \pm 16$ \\
\hline $\begin{array}{c}\text { Vena caval } \\
\text { occlusion }\end{array}$ & $116 \pm 13$ & $\begin{array}{l}1.85 \pm \\
0.60\end{array}$ & $\begin{array}{l}3.02 \pm \\
0.91\end{array}$ & $\begin{array}{l}1.60 \pm \\
0.43\end{array}$ & $\begin{array}{l}2.73 \pm \\
0.92\end{array}$ & $\begin{array}{l}6.5 \pm \\
4.5\end{array}$ & $106 \pm 18$ \\
\hline \multicolumn{8}{|l|}{ Volume load } \\
\hline Subrange I & $106 \pm 12$ & $\begin{array}{l}1.42 \pm \\
0.38\end{array}$ & $\begin{array}{l}2.58 \pm \\
0.68\end{array}$ & $\begin{array}{l}1.63 \pm \\
0.59\end{array}$ & $\begin{array}{l}2.10 \pm \\
0.70\end{array}$ & $\begin{array}{c}16.1 \pm \\
7.3 \dagger\end{array}$ & $133 \pm 16 \dagger$ \\
\hline Subrange II & $105 \pm 11$ & $\begin{array}{l}0.98 \pm \\
0.27\end{array}$ & $\begin{array}{l}1.98 \pm \\
0.42 \dagger\end{array}$ & $\begin{array}{l}0.98 \pm \\
0.67\end{array}$ & $\begin{array}{l}1.40 \pm \\
0.35 \dagger\end{array}$ & $\begin{array}{c}27.2 \pm \\
5.8^{*}\end{array}$ & $148 \pm 31 *$ \\
\hline
\end{tabular}

Values are means $\pm \mathrm{SD} .{ }^{*}$ denotes $\mathrm{p}<0.01$ and $+\mathrm{p}<0.05$ when compared to control state.

\section{DisGussion}

As pointed by Frank, ${ }^{17}$ ) there are basically two systems for recording precordial vibrations, namely displacement and pressure (force) transducers, for 
isometric and isotonic measurement respectively. A close relationship exists between two methods. ${ }^{18}$ ) We have prefered to use calibrated displacement apexcardiography in view of its inherent simplicity and because it is more closely related to the findings obtained during clinical examination.

A marked similarity in time course and contour (especially in isometric phases of cardiac cycle) between left ventricular pressure and $\mathrm{dP} / \mathrm{dt}$, on one hand, and left apex cardiogram and $\mathrm{dA} / \mathrm{dt}$, on other hand, has been repeatedly observed in dog ${ }^{15,181-21)}$ and man. ${ }^{1 /-4), 15)}$ By normalizing the first derivative of apical displacement $(\mathrm{dA} / \mathrm{dt} / \mathrm{A})$ and first derivative of left ventricular pressure $(\mathrm{d} / \mathrm{dt} / \mathbf{P})$, many authors ${ }^{1-4)}$ obtained an exellant correlation between them. Denef et $\mathrm{al}^{22}$ ) using force transducer for calibratied left apex cardiogram and its first derivative investigated peak velocity of contractile element shortening (peak VCE). Under various hemodynamic conditions, they found a highly significant correlations between invasively and noninvasively obtained peak VGE.

This study makes evident for the first time the applicability of displacement calibrated ACG and its first derivative to the quantitative study of the force-velocity properties of the heart muscle. Thus, the determinations of VCE, construction of the isovolumic noninvasive pressure-velocity curve and extrapolation to Vmax provided a sensitive index of contractility. In this study, it was observed that $\mathrm{Vpm}$ were elevated during the administration of isoprenalin and strophanthin. With moderate varying afterload or volume load in both subranges I there were no significant changes in Vpm and Vmax. At extreme elevation of aortic pressure and preload (subranges II), however, only the index Vmax tended to diverge significantly. The reason for this decline of Vmax is not clear. It may, however, represent reflex withdrawal of sympathetic activity to the intact ventricle consequent to stimulation of baroreceptors in the systemic arterioles and in the low pressure vascular compartments within the chest. ${ }^{23)}$ It has been shown in experimental and clinical studies ${ }^{5,77,9)}$ that Vmax is independent of variation in LVEDP and aortic pressure; Nejad et al $^{24}$ reported loading dependence of Vmax. Only Mechmel and co-workers ${ }^{25}$ found changes in $\mathrm{Vpm}$ with varying in pressure load in dog experiments.

In conclusion, the results from this study suggest that myocardial contractility can be assessed nonivasively from calibrated displacement apexcardiography by indexes $\mathrm{Vpm}$ and Vmax, furthermore Vpm is relatively load independent, whereas $V \max$ is virtualy changed over a broad range of loading conditions. 


\section{References}

1. Motomura M, Omae M, Uehata H, Kumata T, Yaginuma T, Wakabayashi A, Konishi T: An apex cardiographic index " (peak $\mathrm{dA} / \mathrm{dt}$ )/ $\mathrm{A}$ " for the assessment of left ventricular function. Jpn Circulat J 37: 1355, 1973

2. Denef B, Popeye R, De Geest H, Kesteloot $H$ : On the clinical value of calibrated displacement apexcardiography. Circulation $51: 541,1975$

3. Van de Werf F, Piessens J, De Geest H, Kesteloot H: Normalized first derivative of the left apex cardiogram in assessment of left ventricular function. Am J Cardiol 37: 1059, 1976

4. Van de Werf F, Piessens J, De Geest H, Kesteloot H: Mechanocardiographic assessment of left ventricular function in coronary artery disease. Brit Heart J 43: 184, 1980

5. Mason DT, Spann JF, Zelix R: Quantification of the contractile state of the intact human heart. Maximal velocity of contractile element shortening determined by the instantaneous relation between the rate of pressure rise and pressure in left ventricle during isovolumic systole. Am J Cardiol 26: 248, 1970

6. Mason DT, Zelis R, Amserdam EA, Massumi RA: Clinical determination of left ventricular contractility by hemodynamics and myocardial mechanecs. Progress in Cardiology, Lea and Febiger, Philadelphia, p 138, 1972

7. Wolk MJ, Keefe JF, Bing OHL, Finkelstein LJ, Levine HJ: Estimation of Vmax in auxotonic systoles from the rate of relative increase of isovolumic pressure: $(\mathrm{dp} / \mathrm{dt}) \mathrm{kp}$. J Clin Invest 50: 1276,1971

8. Mirsky I, Ellison RC, Hugenholz PG: Assessment of myocardial contractility in children and young adults from ventricular pressure recordings. Am J Cardiol 27: 359, 1971

9. Levine HJ, McIntyre KM, Lipana JG, Bing OHL: Force-velocity relations in failing and nonfailing hearts of subjects with aortic stenosis. Am J Med Sci 259: 79, 1970

10. Ross J Jr, Covell JW, Sonnenblick EH: Contractile state of the heart characterized by forcevelocity relations in variabily afterloaded and isovolumic beats. Cadiovasc Res 18: 149, 1966

11. Taylor RR, Ross J Jr, Covell JW, Sonenblick EH: Quantitative analysis of left ventricular function in the intact sedated dog. Circulat Res 21: 99, 1967

12. Grossman W, Haynes R, Paraskos JA, Salsz S, Dalen JE, Dexter L: Alterations in preload and myocardial mechanics in the dog and man. Circulat Res $31: 83,1972$

13. Geddes LA: The Direct and Indirect Measurement of Blood Pressure, Year Book Medical Publishers, Inc, Chicago, 1970

14. Wayne $\mathbf{H H}$ : Noninvasive Technics in Cardiology, Year Book Medical Publishers, Inc, Chicago, 1973

15. Gabor G, Porubsky I, Kalman P: Determination of systolic time intervals using the apex cardiogram and its first derivative. Am J Cardiol 30: 217, 1972

16. Pollak GH: Maximum velocity as an index of contractility in cardiac muscle. Circulat Res 26: 111,1970

17. Frank O: Zur Dynamics des Herzmuscles. Z Biol 32: 370, 1985, translated by Chapman CB, Wasserman E, Am Heart J 58: 282, 1959

18. Willems J: The Normal Apexcardiogram, Arscia, Brussels, 1973

19. Kolev NS, Uzunov GK, Vlasakov VL, Tijaneva JG: Influence of acute hemodynamic changes on the positive peak of the first derivative of apex cardiogram in dogs. Acta Med Hungarica, in press, 1982

20. Willems J, Kesteloot $\mathrm{H}$, De Geest $\mathrm{H}$ : Influence of acute hemodynamic changes on the apex cardiogram. Am J Cardiol 29: 504, 1972

21. Manolas J, Rutishauser $W$, Wirz $P$, Arbenz U: Time relations between apex cardiogram and left ventricular events using simultaneous high-fidelity tracings in man. Brit Heart $\mathrm{J} 37$ : 1263,1975

22. Denef B, De Geest $\mathbf{H}$, Kesteloot $\mathrm{H}$ : Influence of changes in myocardial contratility on the height and slope of the calibrated apex cardiogram. Am J Cardiol 32: 662, 1973 
23. Clancy RL, Gracham TP, Ross J Jr, Sonenblick EH, Braunwald E: Influence of aortic pressure-induced homeometric autoregulation on myocardial performance. Am J Physiol 214: 1186,1968

24. Nejad NS, Klien MD, Mirsky I, Lown B: Assessment of myocardial contractility from ventricular pressure recordings. Cardiovasc Res 1: 15, 1971

25. Mechmel H, Karaembuehl HP, Rutishauser W: Peak measured velocity of shortening in the canine left ventricle. J Appl Physiol 29: 637, 1970 